\title{
RECURSOS FINANCEIROS NA ESCOLA: VISÃO DE DIRETORES EM CINCO MUNICÍPIOS DO CEARÁ
}

\section{RECURSOS FINANCIEROS EN LA ESCUELA: VISIÓN DE DIRECTORES EN CINCO MUNICIPIOS DE CEARA}

\section{FINANCIAL RESOURCES AT SCHOOL: THE PRINCIPALS VISION IN FIVE CITY MUNICIPALITIES FROM CEARA}

\author{
Esmeraldina Januário de SOUSA ${ }^{1}$ \\ Eloisa Maia VIDAL ${ }^{2}$ \\ Sofia Lerche VIEIRA ${ }^{3}$
}

RESUMO: O artigo analisa percepções de nove gestores escolares de cinco municípios do Ceará quanto aos recursos financeiros que chegam às escolas. $\mathrm{O}$ material coletado foi analisado com técnicas de análise do conteúdo de Bardin. A pesquisa mostra que a transferência de recursos federais (PDDE, Mais Educação e Mais Alfabetização) está institucionalizada e são considerados importantes para a gestão do cotidiano da escola. Três dos cinco municípios possuem iniciativas de descentralização de recursos financeiros para as escolas a partir de critérios específicos. Os diretores reconhecem a importância do recurso como apoio a autonomia escolar e informam que as decisões sobre a aplicação são tomadas de forma colegiada com o Conselho Escolar ou com a Unidade Executora. Percebeu-se também que os diretores vêm se apropriando de conhecimentos técnicos e procedimentais sobre a gestão de recursos públicos, e ampliando os saberes sobre aspectos relativos a orçamento, regras de aquisição e prestação de contas.

PALAVRAS-CHAVE: Financiamento da educação. Descentralização de recursos financeiros. Gestão escolar. Autonomia. Administração pública.

RESUMEN: El artículo analiza las percepciones de nueve administradores escolares de cinco municipios de Ceará con respecto a los recursos financieros que llegan a las escuelas. Se analizó el material recogido utilizando las técnicas de análisis de contenido de Bardin. La investigación muestra que la transferencia de recursos federales (PDDE, Más educación y más alfabetización) está institucionalizada y se considera importante para la gestión del día a día escolar. Tres de los cinco municipios tienen iniciativas de descentralización de estos recursos financieros para escuelas desde criterios específicos. Los directores reconocen la importancia del recurso como un apoyo para la autonomía escolar y relatan que las decisiones sobre la aplicación se toman conjuntamente con la Junta Escolar o la Unidad Ejecutora. También se observó que los directores se han apropiado del conocimiento técnico y de procedimientos

1 Universidade Estadual do Ceará (UECE), Fortaleza - CE - Brasil. Mestranda em Educação. ORCID: http://orcid.org/0000-0003-3349-0838. E-mail: esmeraldinajs@gmail.com

${ }^{2}$ Universidade Estadual do Ceará (UECE), Fortaleza - CE - Brasil. Professora Associada do Programa de Pósgraduação em Educação. ORCID: http://orcid.org/0000-0003-0535-7394. E-mail: eloisamvidal@yahoo.com.br.

${ }^{3}$ Universidade Estadual do Ceará (UECE), Fortaleza - CE - Brasil. Professora Titular do Programa de Pósgraduação em Educação. ORCID: http://orcid.org/0000-0002-0271-6876. E-mail: sofialerche@gmail.com

RPGE- Revista on line de Política e Gestão Educacional, Araraquara, v. 24, n. 1, p. 132-153, jan./abr., 2020. e-ISSN: 1519-9029. 
sobre la gestión de los recursos públicos y han ampliado la comprensión sobre los aspectos presupuestarios, las normas de adquisición y la rendición de cuentas.

PALABRAS CLAVE: Financiación de la educación. Descentralización de recursos financieros. Gestión escolar. Autonomía. Administración publica.

ABSTRACT: The article analyses perceptions of nine school principals from five municipalities of Ceara regarding the financial resources flowing to the schools. The collected material was analysed using Bardin content analysis techniques. Research shows that the transfer of federal funds (PDDE, More Education and More Literacy) is institutionalized and is considered important for the school daily management. Three of the five municipalities have financial resources decentralization initiatives for schools from specific criteria. The principals recognize the importance of the resource as a support for school autonomy and inform that the decisions regarding its applicability are taken jointly with the School Board or the Executing Unit. It was furthermore noticed that the principals have been appropriating technical and procedural knowledge about the management of public resources, and expanding the understanding about budget aspects, procurement rules and accountability.

KEYWORDS: Education funding. Financial resources decentralization. School management. Autonomy. Public administration.

\section{Introdução}

Este artigo é produto de uma pesquisa realizada junto a cinco municípios cearenses Fortaleza, Sobral, Maracanaú, Canindé e Limoeiro do Norte - que teve como objetivo investigar aspectos das políticas municipais em relação à avaliação educacional, formação de professores e gestão financeira. A pesquisa se caracteriza como de natureza qualitativa, com estudo de caso múltiplos, utilizando bases de dados secundárias oficiais provenientes do Instituto Nacional de Estudos e Pesquisas Educacionais Anísio Teixeira (Inep), do Fundo Nacional de Desenvolvimento da Educação (FNDE), do Portal da Transparência e outros, e dados primários, obtidos por meio de pesquisa de campo, com uso de entrevistas semiestruturadas junto aos secretários municipais de educação, equipes técnicas e gestores escolares.

Em cada município foram visitadas duas escolas - a de mais alto e a de mais baixo Índice de Desenvolvimento da Educação Básica (Ideb) - sendo entrevistado(a) o(a) diretor(a) ou equipe gestora, totalizando nove $\mathrm{e}^{4}$ depoimentos. $\mathrm{O}$ material coletado foi transcrito e, para este estudo, analisado apenas as respostas do tópico Financiamento da educação, com a utilização

\footnotetext{
${ }^{4}$ Houve um caso de uma escola em Canindé/CE, que no dia da entrevista, o diretor não pode comparecer e, por isso, não foi feito o registro. É uma escola denominada de "polo de ensino" que agrupa quatro escolas e que o diretor faz visitas rotineiras as quatro escolas. No dia agendado para a entrevista, o diretor tinha se deslocado, juntamente com o Coordenador Pedagógico, para um roteiro de visitas às escolas.
} 
de técnicas de análise do conteúdo de Bardin (2009), observando a pré-análise, a exploração do material, o tratamento dos resultados obtidos e a interpretação.

Neste artigo, procura-se analisar as percepções dos gestores escolares quanto às questões relacionadas aos recursos financeiros que chegam às escolas. Para tanto, foi organizado um bloco temático com cinco questões: 1) Quais os programas de recursos financeiros que existem na escola? Como é realizado esse gerenciamento? 2) Qual a participação do Conselho Escolar na gestão dos recursos? 3) Existe alguma forma de divulgação da prestação de contas na escola? 4) A escola consegue utilizar todos os seus recursos ou há sobras? 5) Quais os desafios e avanços na gestão dos recursos financeiros na instituição?

$\mathrm{O}$ artigo está dividido em três seções e considerações finais. A primeira discute aspectos relacionados ao financiamento da educação pública brasileira à luz de documentos e especialistas no tema. A segunda aborda as iniciativas dos governos - federal, municipal e estadual - que transferem recursos financeiros diretamente para as escolas, a terceira trata dos avanços e desafios enfrentados pelas escolas na aplicação dos recursos e, as considerações finais.

\section{Financiamento da educação pública no Brasil}

As características da política de financiamento da educação no Brasil são bem conhecidas na produção científica, sendo que a maior parte dos trabalhos tem abordado a questão da descentralização na educação (DOURADO, 2007; COSTA, 2012; CASTRO, 2001, 2007; FONSECA, 2001; OLIVEIRA, 2001; MELO, 2004). Nesse sentido, as preocupações se dirigem para o que acontece no nível dos mecanismos de negociação territorial, de legislação e de gestão de ações públicas entre grupos de lideranças envolvidos em políticas locais.

Outrossim, como alerta Castro (2001, p. 11), “a discussão a respeito do financiamento para a área de educação tem a ver com as condições materiais e com os recursos financeiros que viabilizam a formulação, implementação e avaliação das políticas". O mesmo autor argumenta, também, que a educação costuma ser apontada como prioridade pelos governos, porém, "[...] se tal prioridade existe, ela deveria se manifestar em termos de gastos públicos, principalmente em sua representação econômica, o que permite analisar a importância dessa área social no contexto da economia" (CASTRO, 2007, p. 858-859). 
Documentos internacionais, como a Declaração de Jomtien $(1990)^{5}$, Declaração de Dakar $(2000)^{6}$, Declaração de Jacarta $(2005)^{7}$ e a Declaração de Incheon $(2015)^{8}$ são marcos do compromisso da parceria global pela educação, que reconhecem que os países deveriam gastar pelo menos 6\% de seu Produto Interno Bruto (PIB) e/ou pelo menos $20 \%$ de seus orçamentos nacionais em educação, a fim de alcançar educação de qualidade para todos. Vale ressaltar que, em alguns países, o orçamento nacional para a educação é garantido por legislação, como no caso do Brasil, da Costa Rica e da Indonésia.

No entanto, a Agenda 2030 para o Desenvolvimento Sustentável não contém compromissos financeiros específicos com a educação e, atualmente, os únicos assumidos com financiamento na nova agenda educacional estão incluídos na Declaração de Incheon e o Marco de Ação da Educação 2030. Também são feitas algumas referências ao financiamento da educação na Agenda de Ação de Adis Abeba (AAAA), acordada na Terceira Conferência Internacional sobre Financiamento para o Desenvolvimento, em julho de 2015, embora a linguagem tenha escopo limitado (focaliza apenas a infância) e não comprometida (são feitas referências vagas para incentivar os países a estabelecerem os objetivos apropriados).

A gestão adequada dos recursos educacionais também é condição necessária para a consagração do direito à educação no Brasil. O artigo 206 da Constituição Federal de 1988, ao expressar os princípios sobre os quais o ensino deve ser ministrado, define o princípio da gestão democrática como instrumento de construção pedagógica e controle social dos recursos financeiros na área. Nesse contexto, as ideias de participação e controle social, intimamente relacionadas, podem tornar-se importantes instrumentos, capazes de incrementar o trabalho desses dirigentes e gestores, melhorando, consequentemente, seus resultados (FERREIRA; OLIVEIRA; ALMEIDA; TEIXEIRA, 2016). Ou seja, trata-se de importantes mecanismos de prevenção da corrupção e de fortalecimento da cidadania que devem ser entendidos como formas de distribuição do poder de decisão sobre as políticas públicas entre o Estado e a sociedade.

Embora o responsável pela gestão dos recursos tenha o dever de aplicá-los de acordo com a lei que estabelece a finalidade de cada item, promovendo, assim, o bem-estar de todos, o mau uso dos recursos públicos, seja pelo despreparo ou índole dos dirigentes e gestores dos

\footnotetext{
${ }^{5}$ Conferência Mundial sobre Educação para Todos, em Jomtien, Tailândia, de 5 a 9 de março de 1990.

${ }^{6}$ Texto aprovado na Cúpula Mundial de Educação em Dakar, Senegal, de 26 a 28 de abril de 2000.

${ }^{7}$ Adotada na Conferência Internacional sobre o Direito à Educação Básica como um Direito Humano Fundamental e o Marco Legal para seu Financiamento (parágrafo IV).

${ }^{8}$ A Declaração de Incheon para a Educação 2030 foi aprovada em 21 de maio no Fórum Mundial de Educação (FME) 2015, ocorrido em Incheon, na Coreia do Sul.
} 
órgãos e entidades, têm, cada vez mais, causado prejuízos aos principais destinatários: os cidadãos.

Ao longo da história da educação brasileira, de acordo com Vieira e Vidal (2015) e Pinto (2018), destacam-se três fases relativas ao financiamento: uma diz respeito ao monopólio dos jesuítas (1549 a 1759); a segunda é caracterizada pela forma do subsídio literário ou dotações orçamentárias arbitrárias para a educação e uma terceira, que vigora desde 1934 até os dias atuais, em que há o estabelecimento da vinculação constitucional de recursos para a educação. No que concerne aos resultados da vinculação, Castro (2001, p. 16) aponta que,

[...] apesar da opinião da maioria dos economistas sobre rigidez e engessamento na gestão orçamentária e financeira do Governo, esse mecanismo foi, de fato, uma forma de proteção à área de educação que garantiu, mesmo nas crises econômicas mais graves, um mínimo de recursos para ao setor.

Para Pinto (2018, p. 847), “[...] no Brasil, a sistemática de garantia de recursos para a educação também tem uma longa história" e na visão de Castro (2001, p. 13), a estrutura de financiamento da educação, apresenta-se “[...] mista e complexa, com a maior parte dos recursos sendo proveniente de fontes do aparato fiscal, que é o caso típico dos recursos da vinculação de impostos".

Os recursos públicos destinados à educação têm origem em: a) receita de impostos próprios da União, dos Estados, do Distrito Federal e dos Municípios; b) receita de transferências constitucionais e outras transferências e; c) receita da contribuição social do salário-educação e de outras contribuições sociais.

Monlevade (2007, p. 5) considera que “[...] como decorrência do princípio da democracia republicana e da gestão democrática do ensino público, a escola e as redes de ensino são os sujeitos novos da autonomia da educação escolar, antes concentradas nas hierarquias administrativas". A democracia republicana a que alude o autor está associada ao processo de descentralização da educação pública implementada no escopo de uma política neoliberal dos anos 1990, que defende a descentralização tutelada por mecanismos de responsabilização. Os atores passam a participar do gerenciamento e da fiscalização dos recursos destinados à escola num deslocamento do processo decisório, do centro do sistema, para os níveis executivos mais próximos aos seus usuários. 
De acordo com o parágrafo único do art. 48 da Lei de Responsabilidade Fiscal $(\text { BRASIL, 2000) })^{9}$ a transparência deve ser assegurada mediante incentivo à participação popular e realização de audiências públicas, durante os processos de elaboração e de discussão dos planos, lei de diretrizes orçamentárias e orçamentos. Servirá também para a avaliação das metas fiscais, pois, dessa forma, a comunidade escolar bem como a comunidade externa terão maior acesso à maneira como é utilizado o dinheiro com o qual pagam seus impostos. Porque, como afirmam Reis, Santos e Rios (2002), tão importante quanto os limites para as despesas e dívidas ou as regras para seus cumprimentos é que elas sejam amplamente conhecidas e corretamente divulgadas.

Outrossim, vale destacar também a obrigatoriedade de se tornar público todos os gastos realizados com a verba adquirida. Libâneo et al. (2003) apontam as duas formas de fiscalização dos gastos existentes: a interna e a externa. A interna corresponde ao Poder Executivo que é encarregado pelo controle dos gastos, elaborando balanços e os publicando a cada bimestre. Esta ação é regulamentada no $3^{\circ}$ parágrafo do art. 165 da Constituição Federal e no art. 72 da Lei ${ }^{\circ}$ 9394/96.

O Portal da Transparência, juntamente com a LRF, busca imprimir maior conhecimento dos atos dos gestores públicos, além de permitir um melhor controle da sociedade sobre a administração dos seus recursos, estabelecendo normas de escrituração e consolidação das contas públicas e instituindo novos relatórios a serem emitidos pelos gestores. Ressalta-se aqui a transparência na prestação de contas, a exemplo da transparência governamental, a qual entende-se como “[...] condição necessária, embora não suficiente, para a efetivação de qualquer ordem democrática, na medida em que só há controle efetivo dos governantes se seus atos forem adequadamente informados à sociedade" (LOUREIRO; TEIXEIRA; PRADO, 2008, p. 108). Além disso, apresenta-se como um processo político que se efetiva no contexto da democratização do país e da necessidade de legitimação política dos governantes.

Considerar estudantes, pais/responsáveis, docentes e funcionários na prestação de contas colabora com a formação cidadã da comunidade, que vai aprender a acompanhar o trabalho de outras esferas públicas e adquirir confiança para cobrar deles uma divulgação de gastos correta e clara. Pois, caso não ocorra a concretização do direito democrático à informação, tal fato acarretará, segundo Afonso (2009, p. 15) na “[...] possibilidade de afastamento e alheamento dos cidadãos face ao que acontece nas instituições e organizações públicas ou de interesse público".

${ }^{9}$ Lei Complementar $\mathrm{N}^{\circ} 101$, de 4 de maio de 2000, estabelece normas de finanças públicas voltadas para a responsabilidade na gestão fiscal e dá outras providências.

RPGE- Revista on line de Política e Gestão Educacional, Araraquara, v. 24, n. 1, p. 132-153, jan./abr., 2020. e-ISSN: 1519-9029. 


\section{Financiamento público nas escolas pesquisadas}

No Brasil, o financiamento público da educação básica municipal se dá por meio do Fundo de Manutenção e Desenvolvimento da Educação Básica e de Valorização dos Profissionais da Educação (Fundeb), instituído pela Emenda Constitucional n n 53/2006, cujo montante de recursos provêm de uma cesta de impostos ${ }^{10}$ e da complementação da União. $\mathrm{O}$ Governo Federal, por sua vez, atua junto aos municípios com programas suplementares, cujos recursos são provenientes da cota-parte do Salário Educação ${ }^{11}$, sob a gestão do Fundo Nacional de Desenvolvimento da Educação (FNDE) e que em alguns casos, transfere os recursos diretamente para as escolas.

Com relação às iniciativas que envolvem a transferência de recursos financeiros para as escolas, os gestores participantes da pesquisa afirmaram existir programas federais - Programa Dinheiro Direto na Escola (PDDE), Programa Mais Educação e Programa Mais Alfabetização. Em nível municipal, foram citados o Programa Municipal de Manutenção e Desenvolvimento do Ensino (PMDE) em Fortaleza, o Fundo de Desenvolvimento e Autonomia Escolar (FUNDAE) em Sobral e o Programa de Autonomia Escolar (PAE) em Maracanaú. Em Limoeiro do Norte e Canindé, segundo os diretores, os únicos recursos financeiros que as escolas recebem são o PDDE, o Programa Mais Educação e o Mais Alfabetização, todos federais.

Algumas escolas também citaram o Prêmio Escola Nota 10, uma iniciativa do governo do estado do Ceará, que repassa recursos financeiros para 300 escolas municipais, desde 2008, associado a critérios de desempenho no Sistema Permanente de Avaliação da Educação Básica (Spaece) aplicado ao $2^{\circ}, 5^{\circ}$ e $9^{\circ}$ anos do ensino fundamental.

\footnotetext{
${ }^{10}$ Em cada estado, o Fundeb é composto por 20\% das seguintes receitas: Fundo de Participação dos Estados (FPE); Fundo de Participação dos Municípios (FPM); Imposto sobre Circulação de Mercadorias e Serviços (ICMS); Imposto sobre Produtos Industrializados, proporcional às exportações (IPIexp); Desoneração das Exportações (LC $n^{\circ}$ 87/96); Imposto sobre Transmissão Causa Mortis e Doações (ITCMD); Imposto sobre Propriedade de Veículos Automotores (IPVA); Cota parte de 50\% do Imposto Territorial Rural (ITR) devida aos municípios. Disponível em: https://www.fnde.gov.br/index.php/financiamento/fundeb/sobre-o-plano-ou-programa/funcionamento. Acesso em: 10 mar. 2020.

${ }^{11}$ O Salário-Educação é uma contribuição social destinada ao financiamento de programas, projetos e ações voltados para a educação básica pública, conforme previsto no $\S 5^{\circ}$ do art. 212 da Constituição Federal de 1988. Seus recursos são repartidos em cotas, sendo que: $10 \%$ da arrecadação líquida fica com o próprio FNDE e mais $30 \%$ que correspondente a cota federal que é aplicada no financiamento de programas e projetos voltados para a educação básica, de forma a propiciar a redução dos desníveis socioeducacionais entre os municípios, estados e regiões brasileiras. Disponível em: https://www.fnde.gov.br/ financiamento/salario-educacao. Acesso em: 10 mar.
} 2020. 
A gestão financeira dos recursos públicos na escola pressupõe um ordenador de despesa $^{12}$ que deve se sujeitar a procedimentos de tomadas de contas organizadas e realizadas pelos órgãos de controle interno (contabilidade, controladoria e auditoria) e externo (Tribunal de Contas) da Administração Pública, em qualquer de suas esferas governamentais.

Os tópicos a seguir retratam as percepções dos gestores escolares acerca dos programas que repassam recursos financeiros.

\section{Programas federais}

Gerenciado pelo Fundo Nacional de Desenvolvimento da Educação (FNDE), autarquia vinculada ao Ministério da Educação (MEC), o Programa Dinheiro Direto na Escola (PDDE) teve início em 1995, no governo de Fernando Henrique Cardoso e foi o primeiro programa de transferência de recursos financeiros da União diretamente para as escolas públicas. Uma das características do PDDE é a descentralização de recursos por meio da prestação de assistência financeira suplementar a todas as escolas públicas de educação básica (estaduais, municipais e do Distrito Federal) e às escolas privadas de educação especial mantidas por entidades sem fins lucrativos.

Segundo o site do FNDE, o objetivo do programa consiste na melhoria da estrutura física e pedagógica das escolas e no reforço a autogestão escolar nos âmbitos financeiro, administrativo e didático. O que tem como consequência direta a elevação dos índices da qualidade da educação oferecida pelas escolas atendidas, como também, a promoção da universalização do ensino.

O Programa Mais Educação ${ }^{13}$, foi institucionalizado pela Portaria Interministerial $n^{\circ}$ 17/2007 e regulamentado pelo Decreto 7.083/2010 e tem como propósito induzir a ampliação da jornada escolar e a organização curricular na perspectiva da Educação Integral (BRASIL, 2010). Os procedimentos para apoio às escolas obedecem aos mesmos critérios e normativos estabelecidos para o PDDE, e os recursos podem ser aplicados em ressarcimento de monitores, aquisição dos kits de materiais, contratação de pequenos serviços e obtenção de materiais de consumo e permanentes.

O outro programa citado pelos entrevistados foi o Programa Mais Alfabetização, instituído pelo Ministério da Educação (MEC) pela Portaria n ${ }^{\circ}$ 142/2018, associado ao Sistema

12 "Toda e qualquer autoridade de cujos atos resultarem emissão de empenho, autorização de pagamento, suprimento ou dispêndio de recursos" (Decreto-lei Federal n ${ }^{\circ}$ 200/67, art. 80, § $1^{\circ}$ ).

${ }^{13}$ Desde 2016, através da Portaria MEC n 1.144 , passou a denominar-se Programa Novo Mais Educação. 
de Avaliação da Educação Básica (Saeb) e que tem como objetivo fortalecer e apoiar técnica e financeiramente as unidades escolares no processo de alfabetização de estudantes regularmente matriculados nos dois primeiros anos do ensino fundamental. $\mathrm{O}$ apoio técnico é realizado por meio da seleção de um assistente de alfabetização, a cargo das secretarias de educação, por um período de cinco ou dez horas semanais, para cada turma de $1^{\circ}$ e $2^{\circ}$ anos. O assistente deve auxiliar o trabalho do professor alfabetizador, conforme seu planejamento, para fins de aquisição de competências de leitura, escrita e matemática por parte dos estudantes.

A gestão financeira desses programas exige a criação de uma Unidade Executora na escola, que deve ser tipificada como "uma sociedade civil com personalidade jurídica de direito privado, que tem como objetivo gerir a verba transferida"14. Importante destacar que a Unidade Executora não deve ser confundida nem associada ao Conselho Escolar, instância prevista na LDB para fomentar a gestão democrática e participativa da escola.

No que se refere ao PDDE, os diretores foram unânimes em reconhecer a importância desse recurso para a gestão do dia a dia da escola, embora apontem os baixos valores e os atrasos na chegada das parcelas como fatores críticos. No caso dos municípios que não possuem programas de transferência de recursos próprios para as escolas - Limoeiro do Norte e Canindé - a autonomia financeira dos diretores se restringe ao uso dos recursos dos programas federais, que de acordo com eles, é muito pouco para resolver os problemas do cotidiano de uma escola cujo período letivo é de 200 dias, funcionando em prédios que já possuem tempo de existência de 15 anos ou mais e que demandam constantes consertos e manutenção.

O Programa Mais Educação que incentiva a ampliação de jornada escolar é percebido pelos diretores como um apoio financeiro importante para a gestão. Um dos principais focos do programa é a melhoria dos resultados de aprendizagem do ensino fundamental, nos anos iniciais e finais, mais especificamente o $3^{\circ}$ e o $9^{\circ}$ ano do ensino fundamental regular. Na visão de uma diretora, a implementação desse programa "[...] foi um ganho para a gente quando a gente recebeu, em 2009, o Programa Mais Educação. Porque a gente viu que a gente poderia trabalhar no contra turno o reforço. [...] Aí a gente começou a focar (Diretora M).

O Programa Mais Alfabetização, por ser uma inciativa recente do Governo Federal, foi objeto de poucos comentários, inclusive porque algumas das escolas visitadas estavam recebendo a primeira parcela e não tinham experiência acumulada sobre sua execução.

É visível que nos últimos anos, a descentralização dos recursos financeiros para as escolas brasileiras tem aumentado, e a responsabilidade pela gestão desses recursos tem sido

14 Disponível em: http://portal.mec.gov.br/ultimas-noticias/214-296700251/13118-escola-deve-criar-unidadeexecutora-para-receber-recursos. Acesso em: 10 mar. 2020.

RPGE- Revista on line de Política e Gestão Educacional, Araraquara, v. 24, n. 1, p. 132-153, jan./abr., 2020. e-ISSN: 1519-9029. 
assumida pelo governo local. Porém, está descentralização implica a autonomia da escola apenas em nível de execução, ou seja, “[...] a descentralização administrativa se dá apenas nas tarefas secundárias e que não implicam na condição de o Estado assumir novos encargos financeiros" (COSTA, 2012, p. 74).

Assim, as regras continuam sendo norteadas pelo Estado e as instâncias dentro da escola que possuem poder deliberativo, como as Unidades Executoras, apenas executam o que já foi definido centralmente. Ou seja, a escola tem uma autonomia relativa, em que, muitas vezes, dispõe do recurso, mas não pode resolver um determinado problema devido a aspectos burocráticos que limitam as possibilidades de aplicação do recurso.

\section{Programas municipais}

Específico do município de Fortaleza, o Programa Municipal de Manutenção e Desenvolvimento do Ensino (PMDE) foi instituído em 2014 pela Lei Complementar n ${ }^{\circ} 169$ e consiste na transferência de recursos financeiros consignados no Orçamento do Executivo com o objetivo de prestar assistência financeira, em caráter suplementar, às escolas da rede municipal de Fortaleza que possuam alunos matriculados na educação infantil, ensino fundamental e educação de jovens e adultos.

O PMDE se propõe a dar maior autonomia à gestão escolar, uma vez que habilita a própria escola a equacionar pequenas demandas cotidianas, favorecendo o foco no processo de ensino e aprendizagem. Para tanto, foram criadas as Unidades Executoras dos Recursos Financeiros (UERF) em todas as escolas públicas municipais, uma instância diferenciada do Conselho Escolar, e que são responsáveis pelo gerenciamento dos recursos recebidos pela escola.

O depoimento de um dos diretores corrobora a existência e a importância do PMDE para as escolas municipais quando afirma que

Temos os recursos federais e os municipais. O municipal que recebemos aqui na nossa escola é o PMDE. O PMDE só são duas parcelas que deveriam ser anuais, mas, sempre tem algum problema que atrasa. Agora que a gente está recebendo... E o gerenciamento é feito pela Unidade Executora que é formada pelo diretor, que é membro nato, pelo secretário da escola e pelo presidente do Conselho Escolar. E para executar o recurso tem a reunião da Unidade Executora, que define as prioridades que são acordadas na reunião e a gente executa. Esse plano vai para a regional para ser aprovado e a gente executa na medida [...] depois a gente presta conta no Conselho Escolar que tem representante dos alunos, dos pais, dos professores e funcionários (Diretor F2). 
O município de Fortaleza criou um mecanismo específico para a gestão financeira da escola, paralelo ao Conselho Escolar, com [...] "a finalidade de assegurar a gestão democrática da escola no que tange à gestão dos recursos financeiros" (FORTALEZA, 2014). Assim, passam a coexistir duas instâncias colegiadas, com constituições distintas. Embora o presidente do Conselho Escolar participe da UERF, esse movimento pode ser compreendido como um fortalecimento do diretor, cargo indicado pela SME, e possível enfraquecimento do Conselho Escolar, que tem representação mais ampliada. Isso também põe em xeque a dinâmica democrática e o grau de participação dos diversos segmentos que compõe a comunidade escolar.

Outro recurso identificado pelos diretores das escolas de Fortaleza diz respeito ao Prêmio Escola por Excelência em Desempenho (PEMED), instituído pela Lei Complementar $n^{\text {o }} 169 / 2014$ e regulamentado pela Portaria $n^{\circ} 183 / 2015^{15}$, que premia escolas da rede pública municipal de ensino que atingirem os melhores desempenhos no Sistema Permanente de Avaliação da Educação Básica do Ceará (Spaece), mais especificamente no Spaece-Alfa, que avalia alunos do $2^{\circ}$ ano do ensino fundamental.

Enquanto as escolas recebem prêmios em dinheiro, os alunos são premiados com smartphones e os professores recebem premiação em forma de certificados e de elogio publicado em Diário Oficial do município. Em 2018 foram premiadas 104 escolas da rede municipal de Fortaleza, no valor total de $\mathrm{R} \$ 1.705 .000,00$. Esse tipo de recompensa financeira é característico de políticas de accountability que utilizam mecanismos de high stakes e não levam em conta aspectos relacionados a equidade na igualdade de oportunidades.

O Fundo de Desenvolvimento e Autonomia Escolar (FUNDAE) é a iniciativa desenvolvida pelo município de Sobral e constituído por receitas próprias do orçamento municipal, podendo também receber recursos decorrentes de pactos interinstitucionais. De acordo com a Lei Municipal nº 318/2001 (SOBRAL, 2001),

$\S 1^{\circ}$ - Os recursos a serem repassados serão definidos anualmente, tendo percentuais fixos e variáveis. Sua base de cálculo será definida utilizando-se como critério o número de alunos matriculados na Educação Infantil, Ensino Fundamental e Educação de Jovens e Adultos, de acordo com dados extraídos do Censo Escolar realizado no exercício anterior, bem como os indicadores de qualidade ensino/aprendizado, e repassada diretamente à unidade executora representativa da Comunidade Escolar em conta específica.

Por meio dessa lei, as escolas têm garantida sua autonomia financeira para despesas de custeio que englobam contas de energia, água e afins, material de consumo, reparos gerais,

${ }^{15}$ No ano de 2018 foram anunciadas novas regras/atualizações do PEMED através da Portaria $n^{\circ} 0659$.

RPGE- Revista on line de Política e Gestão Educacional, Araraquara, v. 24, n. 1, p. 132-153, jan./abr., 2020. e-ISSN: 1519-9029. 
limpeza, manutenção de equipamentos e pequenos investimentos para a melhoria das condições de ensino, além de eventuais gastos com material de ensino e formação docente, que devem ser deliberados, controlados e reportados trimestralmente pela gestão e pelo Conselho de cada escola.

Isso é corroborado na fala da diretora de uma das escolas pesquisadas em Sobral, quando afirma que

Nós temos hoje o FUNDAE, do município. O município disponibiliza mensalmente esse valor para a escola pagar seus utilitários: água, luz, telefone, gás, material de limpeza, material de expediente, só manutenção. [...] Nós temos na secretaria de educação um setor de prestação de contas que nós prestamos conta mensalmente do FUNDAE com a prefeitura. É feito uma prestação de contas mesmo, encadernados, tudo direitinho, recibo, nota fiscal, três propostas e as cinco certidões negativas da empresa ganhadora.

A experiência de Sobral no que se refere a descentralização dos recursos financeiros para as escolas é a mais antiga entre os municípios pesquisados e, ao longo do tempo, vem passando por modificações e ajustes, mas sem interrupção.

A exemplo de Fortaleza e Sobral, o Programa de Autonomia Escolar (PAE) é uma iniciativa do município de Maracanaú que proporciona a transferência de recursos para as escolas de sua rede, visando a autonomia financeira. O município instituiu o PAE por meio da Lei Municipal no 1.096/2006, e tem como objetivo "restabelecer as condições de estrutura física, inclusive de adequação de espaço e de equipamentos das escolas da Rede Municipal de Ensino, além de descentralizar as ações de manutenção das escolas" (MARACANAÚ, 2006, p. $1)$.

De acordo com Moreira (2018, p. 148), ampliando o que prevê a lei de 2006,

a Lei Municipal $\mathrm{n}^{\mathrm{o}}$ 1.205/2007 (de 04/05/2007) estabeleceu que, anualmente, até o limite de $80 \%$ das receitas do salário educação serão destinadas ao PAE e rateados para cada escola na proporção do total de alunos, sendo que, no caso de estudantes de educação integral, os mesmos são contados em dobro. Com essa nova legislação, o recurso passou a ser transferido a todas as escolas a partir de 2008.

Quando inquiridos sobre qual a participação do Conselho Escolar na gestão dos recursos foi possível constatar que há um entendimento comum por parte dos diretores, que diz respeito às decisões coletivas de como os recursos serão aplicados, elegendo-se prioridades, como é possível observar nos depoimentos

[...] eu apresento as prioridades, mas quem decide é o Conselho. Geralmente, claro, por eu ser considerada por eles uma boa gestora, eles confiam. Nós 
não temos pendência na prestação de contas, não temos diligência, todas as minhas conselheiras nunca foram barradas em algum documento... (Diretor M1).

O que eu for comprar tem que ser chamado o Conselho; o conselho analisa e vê se a escola está mesmo precisando, aí compra. O cheque tem que ser assinado pela presidente da unidade executora, só sai se ela assinar o cheque. Eu só faço prestar as contas, ela é quem assina (Diretor M2).

O Conselho Escolar nesse município tem uma participação ativa na gestão financeira, no entanto, não há indícios que apontem participação e integração com a gestão em outros aspectos que possam ser considerados como de interesse para comunidade intra e extraescolar. Nesse sentido, Gino e Bernado (2018, p. 181) alertam que

A garantia legal de certos mecanismos de gestão democrática se constituiu em uma importante conquista para a organização das escolas públicas brasileiras dentro de uma perspectiva crítica e transformadora, especialmente pela institucionalização dos conselhos escolares e da participação dos profissionais da educação na elaboração dos PPP.

O MEC (BRASIL, 2004) aponta que é atribuição do Conselho Escolar deliberar sobre questões político-pedagógicas, administrativas, financeiras; analisar, empreender e viabilizar o cumprimento das finalidades da escola; representar a comunidade escolar e local. A existência do Conselho Escolar com uma atuação efetiva sobre os destinos dos recursos que chegam à escola, e no caso de Maracanaú são expressivos, representa um avanço no processo de democratização da gestão escolar e protagonismo da comunidade sobre os destinos da escola, embora a participação ainda seja restrita a questões financeiras.

Importante observar que as relações entre Conselho Escolar, Unidade Executora e/ou Unidades Executoras dos Recursos Financeiros (UERF) são epistemologicamente distintas, embora em alguns municípios ocorra interseção de membros, que pertencem a um e a outro desses mecanismos, com é o caso de pessoas responsáveis pela gestão, professores e representantes das famílias.

No entanto, ainda persistem equívocos sobre a atribuição dessas instâncias como é possível observar no depoimento de uma diretora de Canindé,

$E$ É, porque tem uma particularidade também na escola. [...] porque nós sabemos que a unidade executora é para esse fim, e o Conselho Escolar uma outra finalidade. E o que muito me surpreendeu na escola municipal é que eles consideram a unidade executora como conselho da escola. Então, se transforma em uma unidade só. [...] eu pretendo depois que normatizar, regularizar toda a questão da unidade executora, a gente deixar como unidade executora para fins [...] é, de recursos financeiros, e... e a gente montar, criar um verdadeiro um Conselho Escolar, para que esse, esse 
conselho ajude... é... não só na parte da gestão administrativa da escola, mas também principalmente, tenha um olhar no pedagógico, no acompanhamento (Diretor C1).

Em certa medida, esse tipo de confusão sobre a coexistência de instâncias colegiadas no interior da escola, confirma o que Conti e Silva (2010, p. 68) alertam quando afirmam que:

Há ainda o desafio da superação de práticas que parecem democráticas: as novas estratégias de "maquiar" a coletivização das decisões através de artimanhas discursivas que insistem em afirmar que já alcançamos nosso ideal, ocultando talvez o desejo daqueles que, a todo custo, buscam impedir o processo de democratização.

Ao analisar as respostas sobre a existência de alguma forma de divulgação da prestação de contas na escola, todos os entrevistados afirmam que fazem uso desse expediente, como é possível observar pelos depoimentos

Existe. Quando vocês entraram ali (pausa) naquele flanelógrafo tem uma prestação de conta fixada ali. Também tem na sala dos professores, para quando a comunidade entrar e ver. Fora isso quando a gente tem alguma reunião a gente comunica. Só que não é uma prestação de conta detalhada, a gente diz que recebeu recursos e está executando, por exemplo, muito serviço realizando a gente informa para os pais (Diretor F2).

Tem sim. Assim... a prestação de conta a gente convoca uma reunião ordinária pra com os pais de alunos, a comunidade, os alunos, os funcionários e faz a prestação de contas (Diretor C2).

Além da gente prestar contas aqui com os pais, é prestado contas com a Secretaria de educação, que é prestado contas com o setor. Então, ela é dita aqui com os pais, com a unidade executora. Ela é guardada aqui, e na hora que qualquer pai quiser tirar dúvidas, ele é... ela é dada pra pessoa prestar contas. E a gente também fala em reunião de pais, quando é no final do ano, a gente presta conta (Diretor L2).

Os diretores utilizam formas parecidas de publicização como, painéis, flanelógrafos, atas, notas fiscais, para expor as prestações de contas nas escolas que dirigem. Não se percebeu, porém, o uso de instrumentos mais operacionais como livros caixa, sistemas informatizados (próprios ou das Secretarias de Educação), dentre outros artefatos contábeis, para prestação de contas ou controle de recursos. Enquanto agentes públicos ordenadores de despesas, os diretores parecem ter consciência sobre os aparatos legais que orientam a administração de recursos públicos.

Quando inquiridos se a escola consegue utilizar todos os seus recursos, ou há sobras, vários diretores responderam que não há sobras, como é possível perceber nos comentários 
Nunca sobra (risos) normalmente assim os recursos que a gente recebe apesar de vir de muitas fontes, mas é pouco. Os recursos do PMDE a gente recebe aqui uma faixa de trinta mil reais no ano (Diretor F2).

[Risos] Os recursos não são suficientes, né? São insuficientes. Por exemplo, a gente estava sofrendo demais com a falta de uma impressora, que não dá pro tempo de hoje, uma escola não ter uma impressora. Fizemos uma promoção, que a comunidade escolar nos ajudou, e nós compramos essa impressora, nós estávamos sem. Porque o recurso que vem para a escola não dá para comprar uma impressora. Por exemplo, o PDDE vem $R \$$ 5.600,00, para o permanente só é $R \$ 1.120,00$, aí geralmente se compra ventiladores. Estamos precisando até de outras coisas, como armário, mas não está dando para comprar (Diretor L1).

Por outro lado, diretores apontam que existem situações em que são necessários realizar replanejamento dos recursos já disponíveis na escola, como mostra os depoimentos a seguir:

Já fui chamada lá para o recurso do Mais Educação, porque tinha dinheiro demais. Nós utilizamos tudo que estava no nosso plano. Ai uma coisa que eu digo para você também. "Por que sobra recurso?" Porque vou ser bem sincera com você, nós temos um controle muito grande do uso do material. Então, a servidora quando ela tira aquele material que ela vai precisar, nós temos a saída e a entrada... a entrada é quando chega aquele material, e a saída é quando ela tira por data. Então eu sei como ela vai estar usando. E eu disse para ela, nós não vamos usar, porque é público usar à toa e gastar à toa. Então sobra recurso. Se ele está na aplicação ele está correndo... é juros pequeno? É, mas sobra. Então a gente vai utilizando com responsabilidade. Vai reprogramando. Ai o governo federal até fez uma coisa com a gente, se tiver dinheiro demais eu não vou mandar a segunda parcela. Isso desde 2016. (Diretora M1)

[...] Estava com o recurso do PDDE ainda do ano passado, eu não tinha utilizado. Eu reprogramei para 2018. Por quê? Porque eu já tinha material suficiente para eu fechar o ano letivo. [...] Eu faço uma estimativa, se eu sei que o recurso vai chegar semestral, eu vou comprar para seis meses. [....] Se o outro semestre é a mesma quantidade ou então uma semana a mais de aula, então eu vou acrescentar só aquele que eu vou precisar. [...] Então agora eu já disse para o conselho que nós vamos reprogramar, porque eu não tenho necessidade de comprar. Se eu não tenho necessidade de comprar eu não mexo no recurso (Diretor $M 1$ ).

Os depoimentos mostram que os diretores reconhecem a importância da descentralização de recursos financeiros como uma iniciativa importante para a gestão escolar. Mostram também que os cinco municípios encontram-se em estágios diferentes de descentralização de recursos, desde situações de municípios que não transferem nada como Limoeiro do Norte e Canindé, até municípios que fazem chegar às contas das escolas, $80 \%$ da cota-parte do Salário Educação e que autorizam, inclusive a ampliação e reforma dos prédios escolares, como o caso de Maracanaú. 
O que se depreende, por meio dos depoimentos coletados é que os diretores reconhecem a importância desses recursos, são conscienciosos sobre suas aplicações e demonstram conhecimento sobre a gestão de recursos públicos, em aspectos relativos a orçamento, regras de aquisição e prestação de contas. A descentralização de recursos financeiros municipais representa valores muito superiores aos recursos federais, o que faz com que a responsabilidade e a carga de trabalho dos gestores escolares aumentem substantivamente, no entanto, não se registrou reclamação do excedente de trabalho que isso representa. Nos três municípios que possuem iniciativas de transferência de recursos para as escolas, existe na Secretaria Municipal de Educação, um setor para apoiar, orientar e receber as prestações de contas das escolas.

\section{Recursos estaduais}

O Prêmio Escola Nota Dez (PEN10) foi criado no ano de 2009 e alterado em 2015. O prêmio possui duas vertentes: a primeira, de uma política indutora, estimulando as escolas a melhorarem seus resultados, e a segunda, de uma política apoiadora das escolas com baixo desempenho. O Índice de Desempenho Escolar (IDE) ${ }^{16}$, calculado a partir das avaliações do Spaece, é o parâmetro para definição de, no máximo, 150 escolas públicas premiadas pelos melhores resultados nas turmas de $2^{\circ}, 5^{\circ}$ e $9^{\circ}$ ano do ensino fundamental. $O$ índice também ajuda a identificar as escolas públicas, em igual número, com turmas de $2^{\circ}, 5^{\circ}$ e $9^{\circ}$ ano que obtiverem os menores desempenhos para que sejam apoiadas financeiramente pelo estado e pedagogicamente pelas escolas pelas premiadas.

O prêmio é calculado a partir do número de alunos participantes na avaliação do Spaece, e estabelece o valor per capita por aluno de $\mathrm{R} \$ 2.000,00$ para as escolas com melhores desempenho, e de $\mathrm{R} \$ 1.000,00$ para as escolas com menores desempenho. A concessão do prêmio é realizada em duas parcelas, e tanto a escola premiada como a apoiada só recebem o valor integral se cumprirem determinados requisitos. A escola premiada recebe na primeira parcela $75 \%$ do valor, no entanto, o recebimento dos $25 \%$ restantes, referente à segunda parcela, está atrelado ao fato de conservar ou aumentar seu desempenho no Spaece e prestar suporte a escola apoiada. A escola de menor desempenho recebe a primeira parcela correspondente a

${ }^{16}$ O Índice de Desempenho Escolar (IDE) é um indicador que reúne três elementos importantes para a qualidade da educação: a proficiência obtida pela escola no Spaece convertida para uma escala de 0 a 10 , a taxa de participação na avaliação e o fator de ajuste para universalização do aprendizado. Dessa forma, surgem os índices, o IDE-Alfa, o IDE-5 e o IDE-9. O IDE-Alfa busca representar o desempenho de cada escola com relação ao seu processo de alfabetização. O seu cálculo está vinculado aos resultados das avaliações do SPAECE-Alfa. O IDE-5 e o IDE-9 expressam os resultados alcançados, respectivamente, nas avaliações de Língua Portuguesa e Matemática realizadas no $5^{\circ}$ e $9^{\circ}$ anos do ensino fundamental. Disponível em: http://www.spaece.caedufjf.net/wpcontent/uploads/2017/07/CE-SPAECE-2016-RP-MT-9EFEM-WEB.pdf. Acesso em: 10 mar. 2020. 
$50 \%$ do valor obtido e os demais $50 \%$ estão sujeitos a exigência de elevar seu desempenho no exame seguinte, para, no mínimo, 5,0.

Trata-se de uma política visivelmente pautada em ações meritocráticas, a partir da mensuração do desempenho escolar, e implementada no escopo do “(...) regime de colaboração no Ceará, uma das unidades da Federação que costuma ser reconhecida por uma experiência positiva em relação à articulação entre estado e municípios" (VIEIRA; VIDAL, 2013, p. 1080). No período 2007 - 2018 foram contempladas com recursos financeiros 2.239 escolas entre premiadas e apoiadas, sendo que algumas receberam o prêmio ou o apoio mais de uma vez. Ao todo, já foram aplicados $\mathrm{R} \$ 234.901 .173,00$ de recursos do estado em escolas municipais.

Diretores entrevistados em Fortaleza e Sobral falaram sobre esse recurso, que também é encaminhado direto para a escola:

Aí nós temos o Escola Nota 10 que é a premiação do segundo e quinto ano para aquelas escolas que são premiadas. É um recurso bom, ele tem até $20 \%$ para bonificação dos profissionais envolvidos naquele resultado, é do governo do Estado. Nós recebemos um de 180 mil, então dá 36 mil, até $20 \%$ para bonificação. $O$ restante nós vamos fazer aqui uma obra. Nós vamos reformar a escola. Nós estamos aguardando a licitação da Prefeitura, vamos pintar toda a escola, colocar janelas de vidro, construir um deposito, comprar equipamentos, datashow, comprar livros. No último foi 9 mil reais para cada professor (Diretora S1).

[...] o recurso escola nota 10. O único recurso para a gente ficar feliz porque é cinquenta e poucos mil. Recebemos 56 mil, ficamos feliz demais, pintamos a escola todinha, colorida, bonita [...] (Diretora F1).

Embora essa iniciativa do governo estadual não contemple todas as escolas municipais, é expressivo os valores recebidos por aquelas que atingem os critérios estipulados. O PEN10 pode ser considerado como um mecanismo de accountability high stakes, que estimula a meritocracia e classifica as escolas.

\section{Avanços e desafios}

Com relação aos avanços e desafios na gestão dos recursos financeiros nas escolas, o que se depreende dos depoimentos é que o processo de descentralização representa mais autonomia de gestão para as escolas, embora os recursos não sejam suficientes e implique em uma carga de trabalho maior para a equipe responsável pela gestão. Percebeu-se também que a apropriação, por parte dos gestores, dos procedimentos atinentes a administração de recursos públicos não é tarefa simples e exige conhecimentos sobre finanças, contabilidade, orçamento, 
compras públicas, etc., na quase totalidade ignorados pelos cursos de formação inicial de formação de profissionais para educação básica (pedagogia e licenciaturas).

Tais percepções se explicitam nos depoimentos registrados tanto nos avanços como nos desafios, o que evidencia a necessidade de iniciativas permanentes de formação continuada nessas áreas. Por outro lado, as preocupações com a garantia da aprendizagem dos alunos foram pontuadas pelos diretores como um avanço, revelando uma ruptura com o modelo de gestão burocrática, focada mais nos aspectos administrativos. A qualificação dos professores, a utilização das tecnologias digitais de informação e comunicação, a aquisição de livros e materiais didáticos são aspectos da gestão pedagógica que o advento dos recursos financeiros nas escolas, facilita, na visão de grande parte dos diretores entrevistados.

\section{Considerações finais}

Desde a publicação da LDB de 1996, discussões sobre gestão democrática e participativa nas escolas públicas e autonomia de gestão escolar vêm sendo objeto de escrutínio por parte de estudiosos do assunto, bem como dos implementadores de políticas educacionais. Em decorrência do seu caráter polissêmico e da autonomia dos entes federados, tem proliferado uma variedade de propostas e implementados outro tanto de modelos. É nesse vórtice produzido pela gestão democrática e participativa e autonomia escolar que emerge as discussões sobre descentralização dos recursos financeiros para a escola.

A pesquisa realizada nos cinco municípios cearenses com diretores de nove escolas mostra que a transferência de recursos federais como o PDDE, o Mais Educação e o Mais Alfabetização estão institucionalizadas e embora em valores abaixo do desejado são considerados muito importantes para a gestão do cotidiano da escola, especialmente nos municípios que não possuem política de descentralização de recursos financeiros, como Limoeiro do Norte e Canindé.

Mostrou também que são muito diversos os processos de descentralização de recursos financeiros adotados pelos municípios que assim procedem. Cada município adota critérios distintos para repasse de recursos, incluindo situações em que as escolas assumem as responsabilidades de pagamentos das despesas de custeio e serviços públicos (Sobral), até reforma e ampliação de escolas (Maracanaú).

Os diretores, por sua vez, reconhecem a importância do recurso como um apoio a autonomia escolar, informam que as decisões sobre os gastos são tomadas de forma colegiada com o Conselho Escolar ou com a Unidade Executora, e estranhamente não reclamam da 
sobrecarga de trabalho e atribuições que advém da gestão dos recursos financeiros. Percebeuse também que os diretores vêm se apropriando de conhecimentos técnicos e procedimentais sobre a gestão de recursos públicos, e ampliando os saberes sobre aspectos relativos a orçamento, regras de aquisição e prestação de contas.

\section{REFERÊNCIAS}

BRASIL. Lei Complementar n. 101/2000, de 4 de maio de 2000. Estabelece normas de finanças públicas voltadas para a responsabilidade na gestão fiscal e dá outras providências. Diário Oficial da União, Brasília, DF, 5 maio 2000. Disponível em: http://www.planalto.gov.br/ccivil_03/leis/lcp/lcp101.htm. Acesso em 12 ago. 2018.

BRASIL. Ministério da Educação. Secretaria de Educação Básica. Programa Nacional de Fortalecimento dos Conselhos Escolares. Conselhos Escolares: uma estratégia de gestão democrática da educação pública. Brasília: MEC, SEB, p. 59, 2004.

BRASIL. Ministério da Educação e Cultura. Decreto n. 7.083, de 27 de janeiro de 2010. Programa Mais Educação. Brasília: MEC, 2010. Disponível em: http://portal.mec.gov.br/programa-mais-educacao/apresentacao. Acesso em: 24 nov. 2018.

BRASIL. Constituição da República Federativa do Brasil. Brasília, DF: Senado Federal: Coordenação de Edições Técnicas, 2016. Disponível em: https://www2.senado.leg.br/bdsf/bitstream/handle/id/518231/CF88_Livro_EC91_2016.pdf. Acesso em: 27 jul. 2018.

CASTRO, J. A. de. Financiamento da Educação no Brasil. Em Aberto, Brasília, v. 18, n. 74, p. 11-32, dez. 2001. Disponível em:

http://emaberto.inep.gov.br/index.php/emaberto/article/view/2150/2119. Acesso em: 17 nov. 2018.

CASTRO, J. A. de. Financiamento e Gasto Público na Educação Básica: 1995 - 2005. Educação \& Sociedade, Campinas, v. 28, n. 100, p. 857-876, out. 2007. Disponível em: http://www.scielo.br/scielo.php?script=sci_arttext\&pid=S010173302007000300011\&lng=pt\&nrm=iso. Acesso em: 17 out. 2018.

CONTI, C.; LUIZ, M. C. Políticas Públicas e Gestão Democrática: o funcionamento do conselho escolar no sistema municipal de ensino. EDUCAÇÃO: Teoria e Prática, v. 17, n. 29, p. 33-50, jul./dez. 2007. Disponível em: https://www.periodicos.rc.biblioteca.unesp.br/index.php/educacao/article/view/1034/962. Acesso em: 16 set. 2018.

COSTA, C. J. da. Autonomia na gestão financeira das escolas públicas brasileiras. Orientador: Ladislau Dowbor.2012. 124 f. Dissertação (Mestrado em Administração) Pontifícia Universidade Católica de São Paulo, São Paulo, 2012. Disponível em: https://tede2.pucsp.br/handle/handle/1022. Acesso em: 12 set. 2018. 
DOURADO, L. F. Políticas e gestão da educação básica no Brasil: limites e perspectivas.

Educ. Soc., Campinas, v. 28, n. 100, p. 921-946, out. 2007. Disponível em

http://www.scielo.br/scielo.php?script=sci_arttext\&pid=S0101-

$73302007000300014 \& \operatorname{lng}=$ en\&nrm=iso. Acesso em 06 out. 2018.

FERREIRA, R. do N.; OLIVEIRA, A. S. de; ALMEIDA, M. S.; TEIXEIRA, E. A. A Importância do Controle Social na Gestão dos Recursos Públicos. In: SEGeT - Simpósio de Excelência em Gestão e Tecnologia, Eixo Gestão Econômica e Financeira. Resende, RJ. 2016. Disponível em: https://www.aedb.br/seget/arquivos/artigos16/ 21324209.pdf. Acesso em: 16 set. 2018.

FONSECA, M. O Banco Mundial e a gestão da educação brasileira. In: OLIVEIRA, D. A. (org.) Gestão democrática da educação: desafios contemporâneos. 3. ed. Petrópolis, RJ: Vozes, 2001.

FORTALEZA. Lei Complementar n. 169/2014, de 15 de setembro de 2014. Dispõe sobre a Gestão Democrática e Participativa da Rede Pública Municipal de Ensino de Fortaleza, institui o Programa Municipal de Manutenção e Desenvolvimento do Ensino (PMDE), modifica o Estatuto do Magistério de Fortaleza, e dá outras providencias. Diário Oficial do Município, Gabinete do Prefeito, Fortaleza, CE, ano LXI, n. 15.361, p. 1-9, 15 set. 2014. Disponível em: https://diariooficial.fortaleza.ce.gov.br/downloaddiario.php?objectId=workspace://SpacesStore/702ae419-a79c-40e6-b3b24dcf4ba453aa;1.1\&numero=15361. Acesso em: 13 set. 2018.

FORTALEZA. Portaria n. 183/2015. Regulamenta o "Projeto Escola com Excelência em Desempenho", no âmbito da Secretaria Municipal de Educação - SME. Diário Oficial do Município, Secretaria Municipal da Educação, Fortaleza, CE, ano LXI, n. 15.588, p. 152-153, 18 ago. 2015. Disponível em: https://diariooficial.fortaleza.ce.gov.br/downloaddiario.php?objectId=workspace://SpacesStore/3b536b27-bd6f-4e2d-9b80891c0e686c2f;1.1\&numero=15588. Acesso em: 13 mai. 2019.

FORTALEZA. Portaria n. 0659/2018. Regulamenta o Programa Escola com Excelência em Desempenho no âmbito da Secretaria Municipal da Educação. Diário Oficial do Município, Secretaria Municipal da Educação, Fortaleza, CE, ano LXI, n. 16.313, p. 35, 18 ago. 2018. Disponível em: https://diariooficial.fortaleza.ce.gov.br/ downloaddiario.php?objectId=workspace://SpacesStore/3b536b27-bd6f-4e2d-9b80891c0e686c2f;1.1\&numero=15588. Acesso em: 13 mai. 2019.

GINO, J. C. de S. A.; BERNADO, E. da S. Gestão Democrática e Utopia Social: a gestão da escola pública na perspectiva de uma outra democracia. Movimento-Revista de Educação, Niterói, ano 5, n. 8, p. 179-209, jan./jun. 2018. Disponível em: http://periodicos.uff.br/revistamovimento/article/view/32651. Acesso em: 11 out. 2018.

GOMES, M. J. O.; MORAES, L. S. A Importância do fluxo de caixa para a organização financeira da Empresa X. Revista Científica Semana Acadêmica. Fortaleza, ano MMXI, n. 000006, 10 jul. 2013. Disponível em: https://semanaacademica.org.br/artigo/importancia-dofluxo-de-caixa-para-organizacao-financeira-da-empresa-x. Acesso em 24 abr. 2019.

LIBÂNEO, J. C.; OLIVEIRA, J. F.; TOSCHI, M. S. (Org.). Educação Escolar: políticas, estrutura e organização. São Paulo: Cortez, 2003. 
MAFASSIOLI, A. da S. 20 anos do Programa Dinheiro Direto na Escola: um olhar crítico sobre as interferências na gestão escolar e financeira pública. Fineduca - Revista de Financiamento da Educação, Porto Alegre, v. 5, n. 12, 2015. Disponível em: https://seer.ufrgs.br/fineduca/ article/view/67555/38751. Acesso em: 18 ago. 2018.

MARACANAÚ. Lei Municipal n. 1.096/2006, de 19 de maio de 2006. Cria o Programa de Autonomia Escolar - PAE, no âmbito do Município de Maracanaú e dá outras providencias. 2006. Prefeitura Municipal. Câmara Municipal de Maracanaú. 2006. Disponível em: https://camaramaracanau.ce.gov.br/leis-municipais-2006/. Acesso em: 27 abr. 2018.

MELO, A. A. S. A mundialização da educação: consolidação do projeto neoliberal na América Latina, Brasil e Venezuela. Maceió: PPGE/CEDU/EdUFAL, 2004. Disponível em: https://searchworks.stanford.edu/view/5825503. Acesso em: 13 nov. 2018.

MONLEVADE, J. A. C. Educação escolar: colaboração e cooperação nas políticas públicas. Conferência Nacional de Educação Básica 2008. Disponível em: http://portal.mec.gov.br/ arquivos/conferencia/documentos/texto_monlevade.pdf. Acesso em 10 jun. 2018.

\section{MOREIRA, A. N. G. A Implementação da Autonomia Financeira da Escola em}

Municípios Cearenses. Orientador: Sofia Lerche Vieira. 2018. 363 p. Tese (Doutorado em Formação de Professores) - Universidade Estadual do Ceará, Centro de Educação, Programa de Pós-Graduação em Educação, Fortaleza-CE, 2018.

OLIVEIRA, R. P. A municipalização do ensino no Brasil. In: OLIVEIRA, D. A. (org.).

Gestão democrática da educação: desafios contemporâneos. 3. ed. Petrópolis: Vozes, 2001.

PINTO, J. M. de R. O Financiamento da Educação na Constituição Federal de 1988: 30 Anos de Mobilização Social. Educ. Soc., Campinas, v. 39, n. 145, p. 846-869, dez. 2018.

Disponível em: http://www.scielo.br/scielo.php?script=sci_arttext\&pid=S010173302018000400846\&lng=pt\&nrm=iso. Acesso em 20 ago. 2019.

REIS, K. M. R. dos; SANTOS, L. M. B. dos; RIOS, M. C. D. Transparência na Gestão Pública. Orientador: Luís Paulo Guimarães dos Santos.2002. 29 f. Monografia (Curso de Pós-Graduação em Contabilidade Pública) - Universidade Federal da Bahia. Salvador, 2002. Disponível em:

https://www.sefaz.ba.gov.br/scripts/ucs/externos/monografias/monografia_katia_lucia_maria. pdf. Acesso em: 16 ago. 2018.

SOBRAL. Lei n. 318/2001, de 12 de setembro de 2001. Institui o Fundo para o Desenvolvimento e Autonomia da Escola - FUNDAE na forma que indica e dá outras providências. Impresso Oficial do Município, Secretaria de Desenvolvimento da Educação, Sobral, CE, ano IV, n. 63, p. 8-10, 24 set. 2001. Disponível em: http://www.sobral.ce.gov.br/ diario/public/iom/IOM63-extra.pdf. Acesso em 26 abr. 2018.

UNESCO. Instituto Internacional de Planejamento Educacional da Unesco.

Microplanejamento da Educação. Fichas Práticas. Descentralização da gestão escolar.

Learning Portal. 2018. Disponível em: https://learningportal.iiep.unesco.org/es/fichaspraticas/improve-learning/ gestion-de-los-sistemas-educativos/descentralizacion-de-lagestion. Acesso em: 5 ago. 2019. 
VIEIRA, S. L.; VIDAL, E. M. Política de financiamento da educação no Brasil: uma (re)construção histórica. Em Aberto, v. 28, n. 93, p. 17-42, 2015. Disponível em:

http://emaberto.inep.gov.br/index.php/emaberto/article/view/2456. Acesso em: 13 nov. 2018.

\section{Como referenciar este artigo}

SOUSA, Esmeraldina Januário de; VIDAL, Eloisa Maia; VIEIRA, Sofia Lerche. Recursos financeiros na escola: visão de diretores em cinco municípios do Ceará. Revista on line de Política e Gestão Educacional, Araraquara, v. 24, n. 1, p. 132-153, jan./abr., 2020. e-ISSN: 1519-9029. DOI: https://doi.org/10.22633/rpge.v24i1.13067

Submetido em: 27/10/2019

Revisões requeridas: $18 / 11 / 2019$

Aprovado em: 28/12/2019

Publicado em: 06/01/2020 